\title{
Experimental Study on the Nonlinear Dynamic Characteristics of Wire Rope under Periodic Excitation in a Friction Hoist
}

\author{
Yongbo Guo $\mathbb{D}^{1},{ }^{1}$ Dekun Zhang $\mathbb{D}^{2},{ }^{2}$ Xinyue Zhang $\mathbb{D D}^{2}$ Songquan Wang $\mathbb{D D}^{1}$ and Wan Ma $\mathbb{i D}^{1}$ \\ ${ }^{1}$ School of Mechatronic Engineering, JiangSu Normal University, Xuzhou 221116, China \\ ${ }^{2}$ School of Materials Science and Engineering, China University of Mining and Technology, Xuzhou 221116, China
}

Correspondence should be addressed to Yongbo Guo; ybguo@jsnu.edu.cn and Dekun Zhang; dkzhang@cumt.edu.cn

Received 27 November 2019; Accepted 23 January 2020; Published 17 February 2020

Academic Editor: Mario Terzo

Copyright (c) 2020 Yongbo Guo et al. This is an open access article distributed under the Creative Commons Attribution License, which permits unrestricted use, distribution, and reproduction in any medium, provided the original work is properly cited.

The nonlinear dynamic responses of a wire rope under periodic excitation in a friction hoisting system are investigated. Longitudinal excitation experiments of different periodic excitation frequencies are performed. The nonlinear dynamic characteristics of the rope, including transverse, longitudinal, and coupled vibrations, are discussed with time-frequency analysis. The results show that the transverse vibration is a forced vibration following the excitation, while the longitudinal vibration shows a complex, random vibration state. The vibration amplitude and intensity deviate significantly from their linear trend (superharmonic resonance) at some excitation frequencies, and this deviation indicates the typical nonlinear multiorder natural frequency characteristics. The lifting motion can lead to additional corrugated high-order harmonics and cause a fundamental wave distortion of low-frequency excitation. Experimental evidence for the coupling characteristics of the transverse-longitudinal rope vibration in the lifting process is found.

\section{Introduction}

The friction hoisting system has a wide range of applications in the field of personnel and material transportation in mines and buildings $[1,2]$. Due to the high axial load capacity and excellent bending properties of the steel wire rope, most hoisting systems use it as a transport medium. In particular, in the friction hoisting system, the volume of the entire system is greatly reduced due to the application of multiple steel wire ropes to bear the same load. Figure 1 illustrates the composition of a typical hoisting system, which includes a driving friction pulley at the upper end, wire ropes attached to the friction pulley, and a hoisting cage (or a balance hammer) suspended at both ends of the rope. Viscoelastic friction linings are attached to the surface of the friction pulley to provide a sufficient friction force for the rope. The friction pulley rotates to drive the rope, which drives the hoisting cage (or the balance hammer) along the track in the shaft. The track system is generally divided into two types: rigid cage guide and flexible cage guide. The rigid cage guide consists of a series of lead rails. The flexible cage guide has been rapidly applied in mine fields in recent years $[3,4]$. It uses the suspended wire rope as the guide rail of the container and has the advantages of low cost, stable operation, and convenient replacement.

During the lifting operation of the friction hoist system, the hoisting cage can be subjected to various external sources of excitation. First, a periodic excitation source is formed to the container due to roller roundness error or supporting spring stiffness difference of the guide shoe roller in the mine hoist cage or bucket $[3,5]$. The transverse stiffness of the rope in the flexible cage guide has obvious periodic alternating characteristics in the acceleration and deceleration stage $[6,7]$. Second, the lifting motion makes the mechanical parameters such as the length, mass, and speed of the rope time-varying, which is the main factor that induces a parametric resonance of the system $[8,9]$. Third, during the lifting process, the wire rope easily forms obvious somatosensory vibration or noise when the container approaches the lifting end point since the vibration frequency increases because the rope length decreases. It is easy to form a structural resonance with other system fixing parts [10]. 


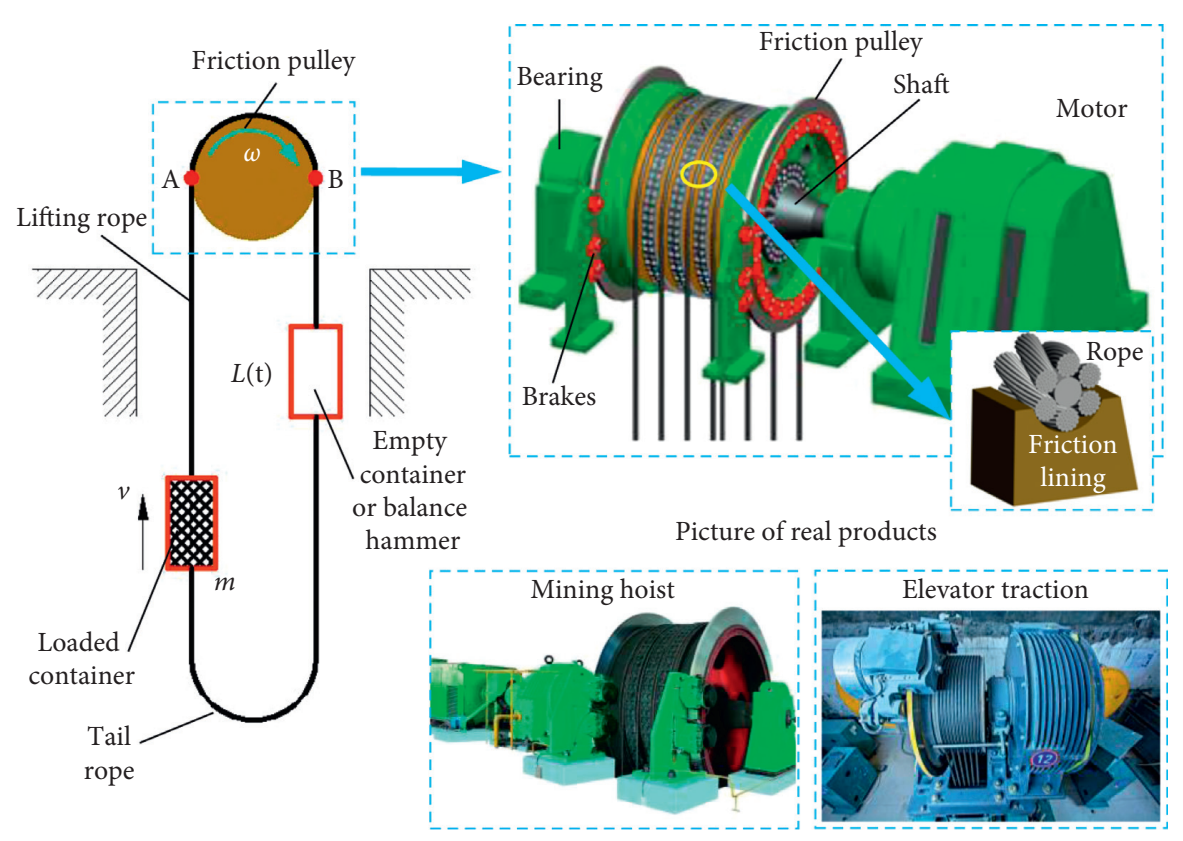

FIgURE 1: Diagram of the multirope friction hoist system.

The occurrence of parametric excitation is very probable because there are many low frequencies in the container or pulley and in the stay cables. When a local (rope) model and a global (structure) mode are coupled, even a very small motion of the cage or pulley may cause dynamic instability and extremely large vibration amplitudes, and the entire system is in dynamic operation [11]. In particular, in recent years, the friction hoisting system is becoming larger and faster with the deepening of underground mines and ground buildings. Vibrations that derive from increasingly obvious wind sometimes cause the fatigue fracture of the steel wire inside the rope $[12,13]$.

These factors will produce or aggravate periodic or fragment periodic vibration excitations on the system. On the one hand, strong container vibrations can easily cause physical discomfort or damage the delicate equipment. On the other hand, the container vibration will induce the vibration of the connected rope. Since the wire rope is a longdistance flexible structure, its vibration has complex characteristics such as modal coupling and directional coupling under periodic excitations [14-16]. The vibration of the rope will be transmitted upward along the rope to the traction friction pulley in the hoisting system. Both longitudinal and transverse vibrations can reduce the effective friction between the rope and the pulley surface [17]. In severe cases, the friction is insufficient, and the rope will slip [18, 19]. Therefore, the study of the rope dynamic response under periodic excitations has an important guiding role in detecting the harmonic excitation response mechanism and suppressing the vibration of the entire friction system.

The periodic excitation method is effective in estimating the rope tension and vibration characteristics [20, 21]. Many scholars have performed rich research on the rope dynamic characteristics under static or quasi-static tension conditions such as bridges and buildings. Lepidi and Gattulli [22, 23] noted that a relevant contribution of higher modes might arise as a result of nonlinear coupling phenomena. The modal interactions in both planar and spatial responses to the periodic in-plane and out-of-plane cable loads were studied using analytical and finite element models. Macdonald $[24,25]$ provided analytical expressions for the steady-state vibration amplitudes of a taut cable with parametric excitation with different mode combinations. Modal instabilities can occur from two mechanisms: (a) nonlinear modal coupling between modes with the same natural frequencies or (b) parametric excitation at half of the excitation frequency because of the axial component of the end motion. Chen and Sun [26] used a continuation method to predict the system responses to a range of excitation frequencies near the cable eigenfrequencies. They found that when the damper was near the cable end, the lower-mode cable vibration was suppressed because higher modes were excited. Yan et al. [27] investigated the dynamic characteristics of the cross-rope suspension tower system under the axial periodic load produced by the galloping of iced transmission ropes. The relationship between the rope system stability and the excitation frequency was identified. Zou et al. [28] proposed a new modification of the homotopy analysis method to capture the asymmetric solutions of wire rope isolation systems with a periodic excitation force. Kang et al. [29] studied the predicting method and automatic resonance avoidance of offshore crane cables to complement the safety management during subsea lowering operation. The study proves that the dynamic instability of the cable at a periodic region of Mathieu stability diagram potentially creates high risk for the lowering operation.

However, under the condition of high-speed and heavyload hoisting, the periodic vibration response of the wire rope is rarely reported. In this paper, experimental equipment is designed to simulate the excitation state of the 
hoisting system during dynamic operation. The transverse and the longitudinal vibration of the rope under different frequencies of excitation are obtained. The typical modal distortion and transverse-longitudinal coupling vibration characteristics of the rope during dynamic hoisting are discussed using the time-frequency analysis. This study complements the lack of research on the periodic excitation response of the hoisting system. The harmonic vibration mechanism of the wire rope is clarified. It provides a theoretical basis to further control the rope vibration and improve the stability of the hoisting system.

\section{Experimental Details}

2.1. Experiment Setup. The experimental principle is shown in Figure 2. The photos of the experiment device are shown in Figure 3. The detailed introduction is shown in [19].

\subsection{Experiment Scheme}

2.2.1. Lifting Parameters. The initial lifting speed and acceleration of the system are shown in Figure 4.

Table 1 lists the parameters of the experiment device.

2.2.2. Excitation Parameters. Figure 5 shows the schematic diagram of the excitation. The excitation frequency is regulated by the speed governor. The governor changes the rotor speed of the excitation motor through the principle of variable voltage and frequency conversion. The excitation motor is internally equipped with an eccentric block. Some eccentric blocks are symmetrically mounted on the motor main shaft to achieve an excitation force along a fixed direction. The excitation force in this experiment is vertical. When the rotation speed varies, the direction of the eccentric force varies, which realizes the excitation force of different frequencies.

To obtain an accurate excitation frequency value, different levels of excitation force are applied to the static rope. The tension responses in $2.5 \mathrm{~s}$ are obtained, as shown in Figure 6 . The higher level represents the higher excitation frequency. When the excitation frequency increases, the "beat frequency" characteristic of the tension signal becomes increasingly prominent $[30,31]$. The beat frequency is similar to the signal "modulation" induced by two approaching signal frequencies.

The time-frequency analysis of each signal is shown in Figure 7. There are $50 \mathrm{~Hz}$ signal components in the timefrequency distribution of different levels of excitation. This is due to the interference caused by the AC power supply. It can be seen that when the excitation frequency is close to $50 \mathrm{~Hz}$, the time-frequency characteristics of the two frequency components produce obvious cross-linking and spacing aggregation. This explains the generation of the "beat frequency" feature of the amplitude in Figure 6.

The relationship between the excitation force and the frequency of the eccentric motor satisfies the following formula:

$$
F_{e}=m_{e} r_{e}=4 \pi m_{e} r_{e} f_{e}=C_{e} f_{e}^{2},
$$

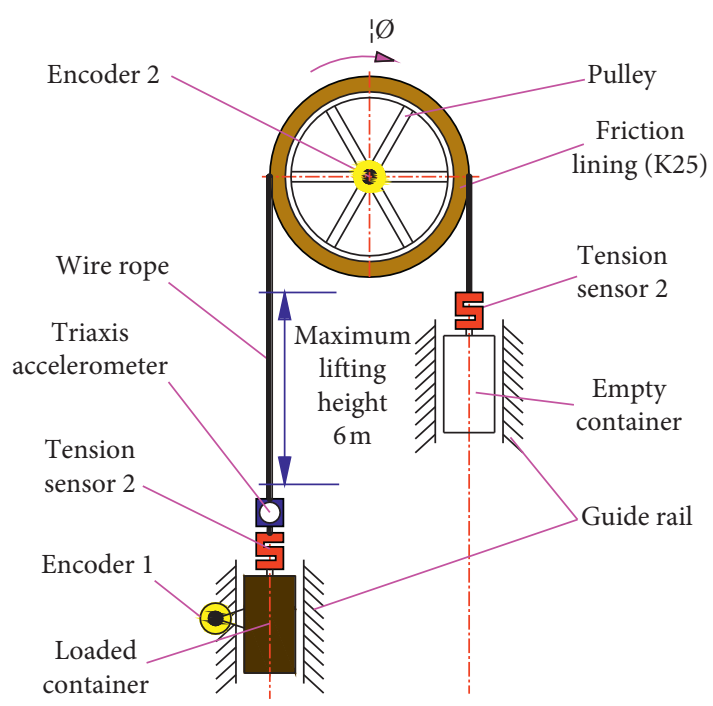

FIgURE 2: Schematic diagram of the dynamic friction transmission experiment device of the friction hoist.

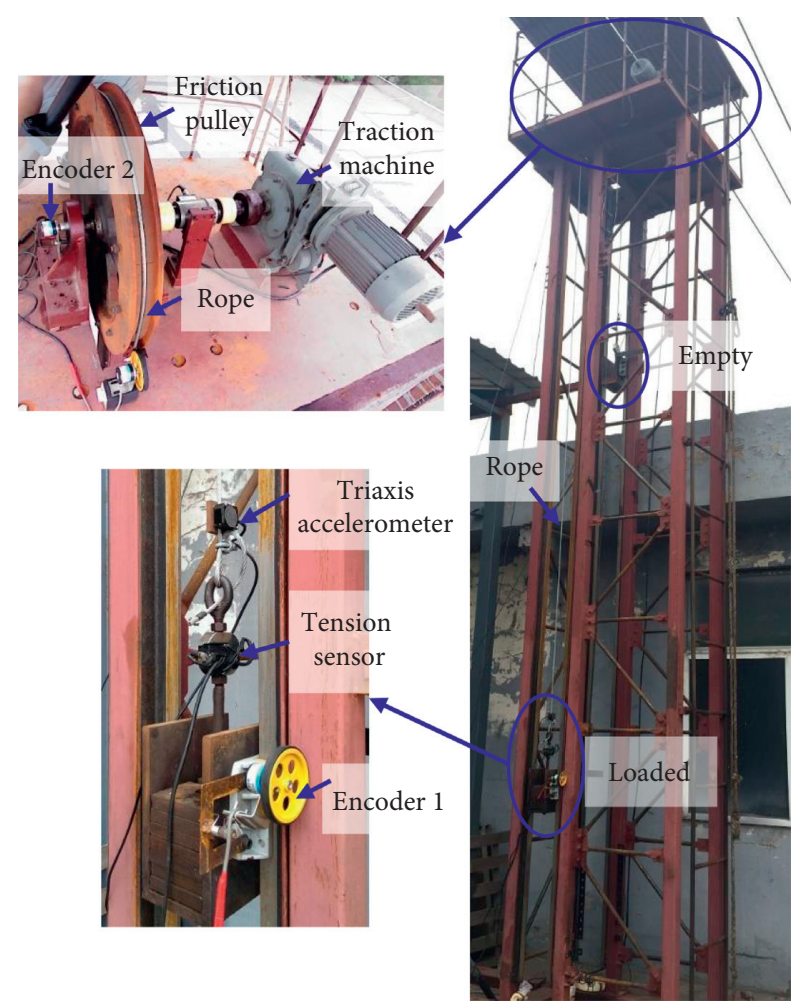

FIgURe 3: Photos of the dynamic friction transmission experiment device.

where $F_{\mathrm{e}}$ is the excitation force, $m_{\mathrm{e}}$ is the eccentric block quality, and $r_{\mathrm{e}}$ is the radius of rotation. The maximum excitation force of $40 \mathrm{~kg}$ can be reached when the full frequency of $50 \mathrm{~Hz}$ is applied. Then, coefficient $C$ can be obtained. According to the formula, the excitation force at different frequencies can be obtained as shown in Table 2.

The control flow used by the experimental platform control system is computer-PLC-inverter-motor. The 


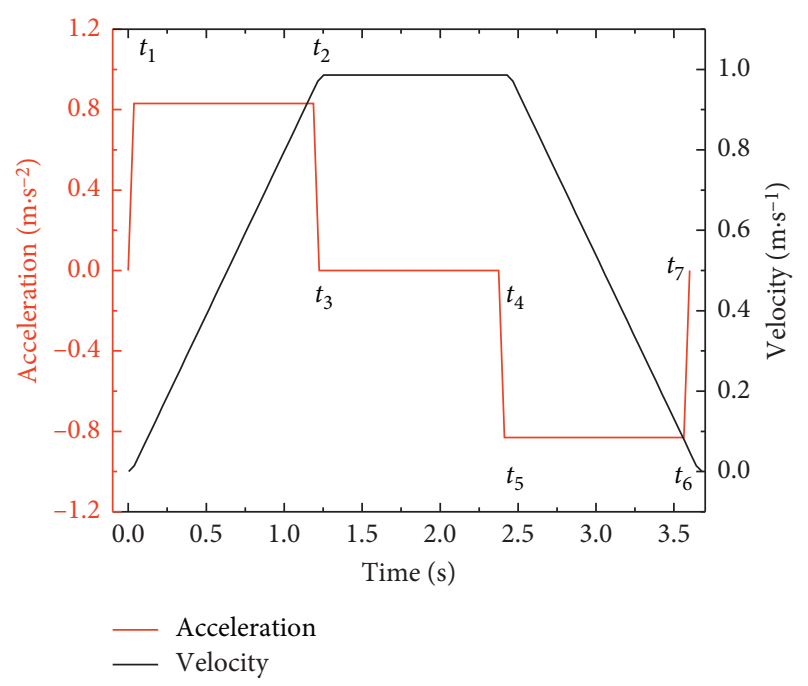

FIGURE 4: Lifting speed and acceleration curve.

TABle 1: Parameters of the experiment device.

\begin{tabular}{lc}
\hline Item & \\
\hline Load mass $(\mathrm{kg})$ & 29.7 \\
Conveyance mass $(\mathrm{kg})$ & 27.5 \\
Pulley diameter $(\mathrm{mm})$ & 640 \\
Wrap angle $\left(^{\circ}\right)$ & 180 \\
Rope type & $6 \times 19 \mathrm{WS}+\mathrm{FC}$ \\
Rope diameter $(\mathrm{mm})$ & 8 \\
Acceleration $\left(\mathrm{m} / \mathrm{s}^{2}\right)$ & 0.83 \\
Maximum speed $(\mathrm{m} / \mathrm{s})$ & 1 \\
Acceleration time $(\mathrm{s})$ & 1.2 \\
Constant-speed time $(\mathrm{s})$ & 1.2 \\
\hline
\end{tabular}

total data acquisition frequency in the experiment is $2 \mathrm{kHz}$, and the single-group acquisition frequency is $500 \mathrm{~Hz}$. Due to the frequency converter, the AC contactor in the experimental equipment control system, and high-voltage environment of the workshop, the signal acquisition will generate certain high-frequency interference. Therefore, the one-dimensional wavelet threshold denoising method is applied to denoise the collected signals $[32,33]$. The specific process is that a wavelet base and a decomposition layer are selected to decompose the signal layer by layer. Then, a certain threshold function and threshold are selected to filter out the noise of each layer of the decomposed signal. Finally, the filtered signals are reconstructed by the wavelet transform to obtain the final signal. The denoising method can improve the signal-to-noise ratio of the signal, highlight the actual signal required, and improve the accuracy of the experimental result analysis.

\section{Results and Discussion}

3.1. Single Excitation Frequency. Figure 8 shows the tension and vibration of the lifting-side rope during the normal lifting process of a lifting cycle. Due to the three-stage speed characteristics of the acceleration, constant speed, and deceleration, the tension distribution of the rope can be

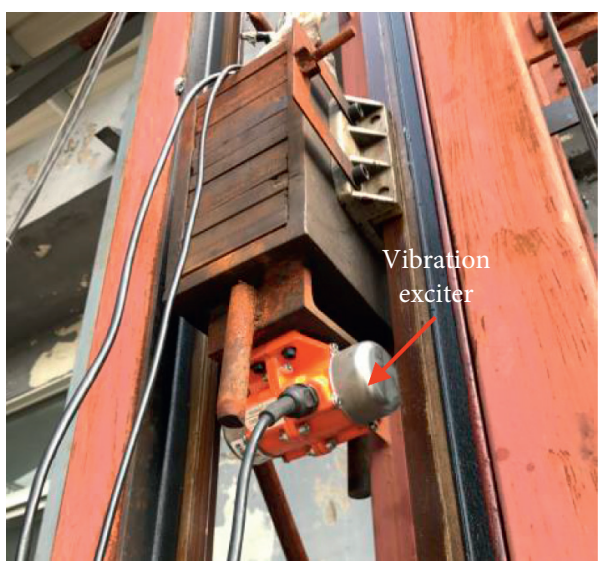

FIgURE 5: Schematic diagram of the excitation.

divided into three stages. The tension at the acceleration stage can be divided into a dynamic tension regime and an inertial tension regime [18]. The transverse vibration is mainly aggravated with the increase in speed. The amplitude of the vibration acceleration is basically symmetric.

In the time-frequency distribution Figure 9, the transverse vibration has many corrugated frequency components at the position of $60 \sim 100 \mathrm{~Hz}$ in the constant-speed stage. The power spectrum has an extreme value of $1407 \mathrm{~m}^{2} \cdot \mathrm{s}$ and appears in the high-frequency range $(90 \sim 100 \mathrm{~Hz})$. This phenomenon is similar to random superharmonic resonance [34]. The longitudinal vibration exhibits a variation law similar to random fluctuations. The strong vibration regime is concentrated in the constant-speed stage, and the individual position is disturbed. The power spectrum is $818 \mathrm{~m}^{2} \cdot \mathrm{s}$, but it occurs in the low-frequency range $(0 \sim 10 \mathrm{~Hz})$. It can be seen from Figures 8 and 9 that the strength of both longitudinal and transverse vibrations is mainly in positive correlation with the movement speed of the wire rope, although the longitudinal tension in the beginning of the lifting stage showed a large fluctuation. But at this time, the wire rope just started to accelerate from 0 . At this time, the running speed is low, so the longitudinal vibration is weak. On the other hand, the period of large fluctuations in tension is relatively long, that is, during the period when the wire rope starts to be pulled by the friction wheel, the wire rope appears to expand and contract gently due to its good elasticity. Therefore, the sudden peak of longitudinal vibration acceleration is difficult to appear.

Figure 10 shows the tension and vibration of the rope when the lifting container is subjected to an excitation frequency of $46.7 \mathrm{~Hz}$. The longitudinal excitation has no obvious effect on the rope tension during the lifting process. Thus, the high-frequency excitation energy is absorbed by the internal elasticity and damping of the wire rope. The longitudinal rope deformation caused by the excitation is small, so the basic characteristics of the macrotension remain unchanged. Compared with the tension, transverse and longitudinal vibrations of the rope under excitation are greatly enhanced. The transverse vibration acceleration slightly increases after the lifting begins compared to the 


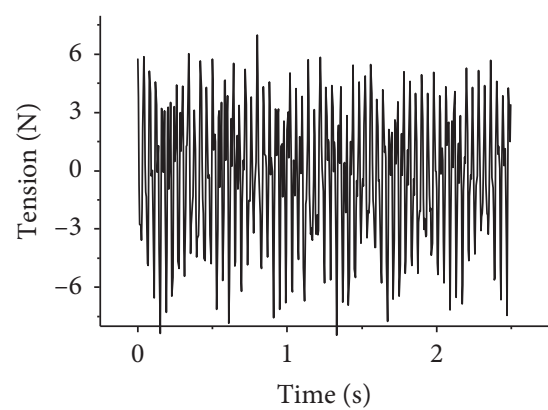

(a)

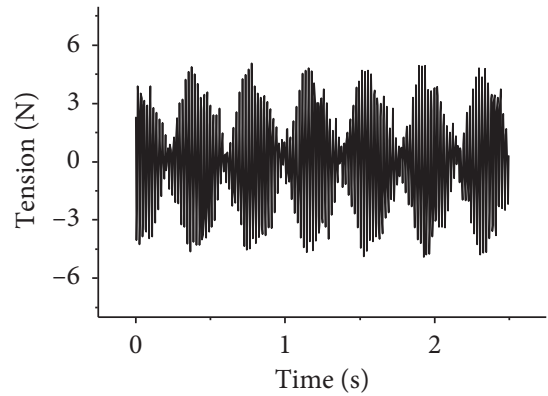

(d)

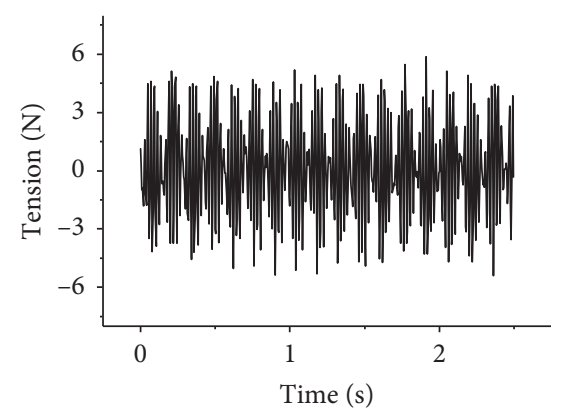

(b)

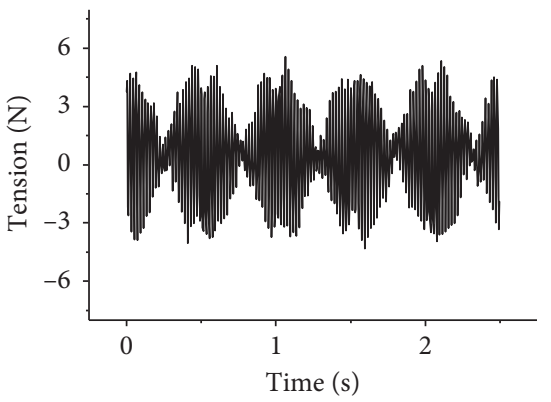

(e)

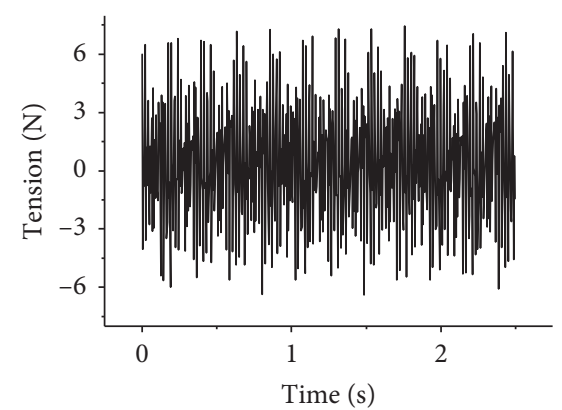

(c)

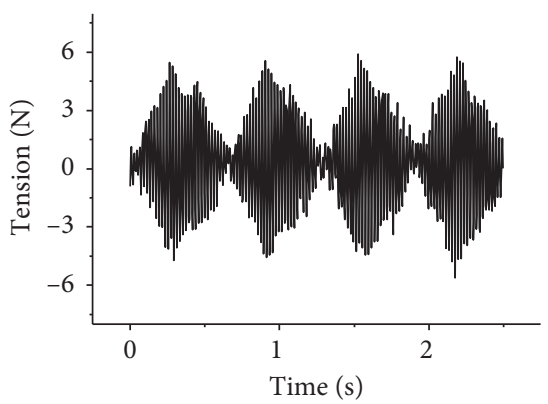

(f)

Figure 6: Tension test signal for the static rope under different excitation grades.

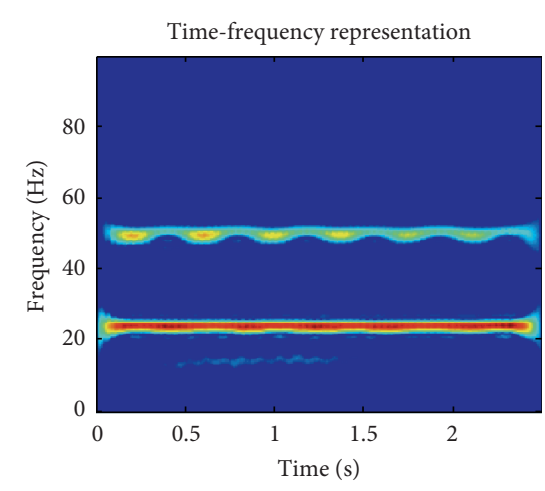

(a)

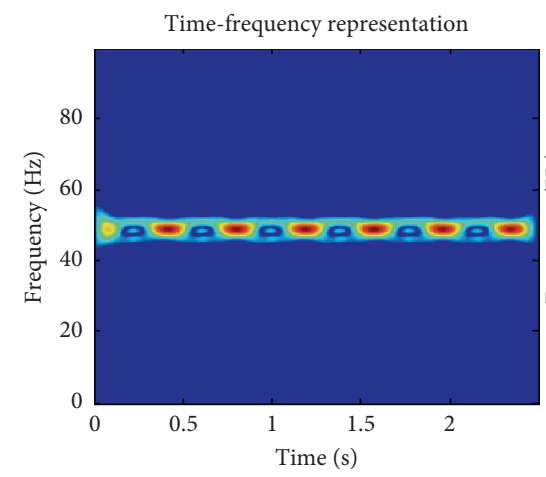

(c)
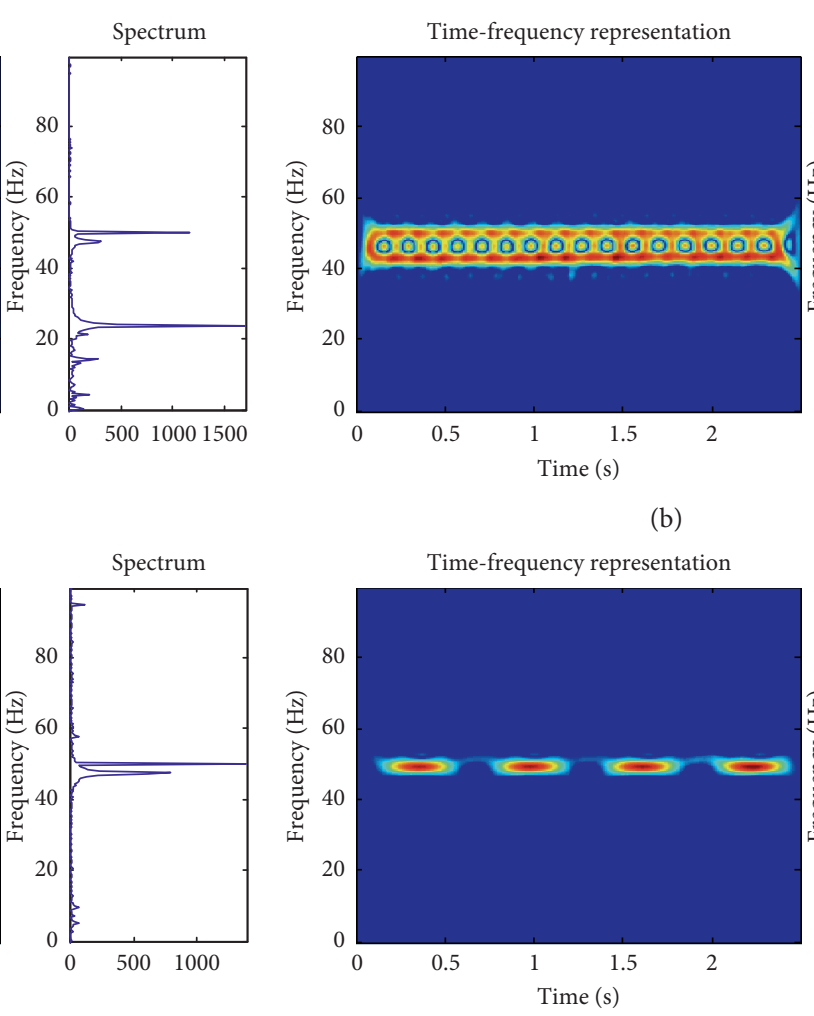

(d)
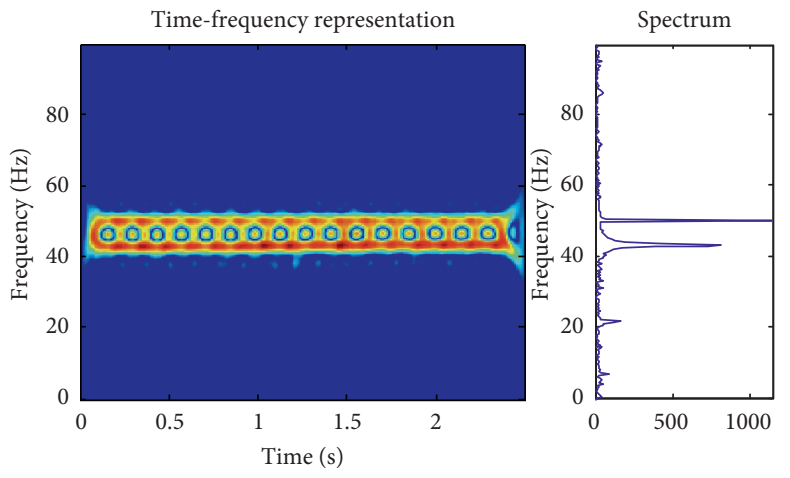

(b)

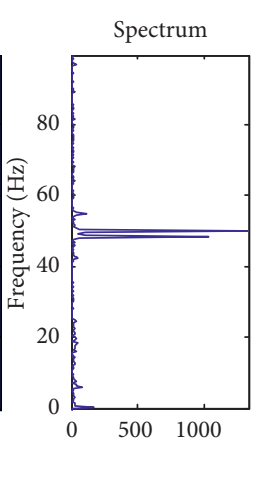

Figure 7: Time-frequency distribution of the tension test signal of static ropes under different excitation forces. 
TABLE 2: Excitation frequency and excitation force.

\begin{tabular}{lccccccc}
\hline Group & 1 & 2 & 3 & 4 & 5 & 6 & MAX \\
\hline Frequency $(\mathrm{Hz})$ & 23.6 & 43.3 & 45.7 & 46.7 & 48.1 & 48.5 & 50 \\
Force $(\mathrm{kg})$ & 8.9 & 30 & 33.4 & 34.9 & 37 & 37.6 & 40 \\
\hline
\end{tabular}

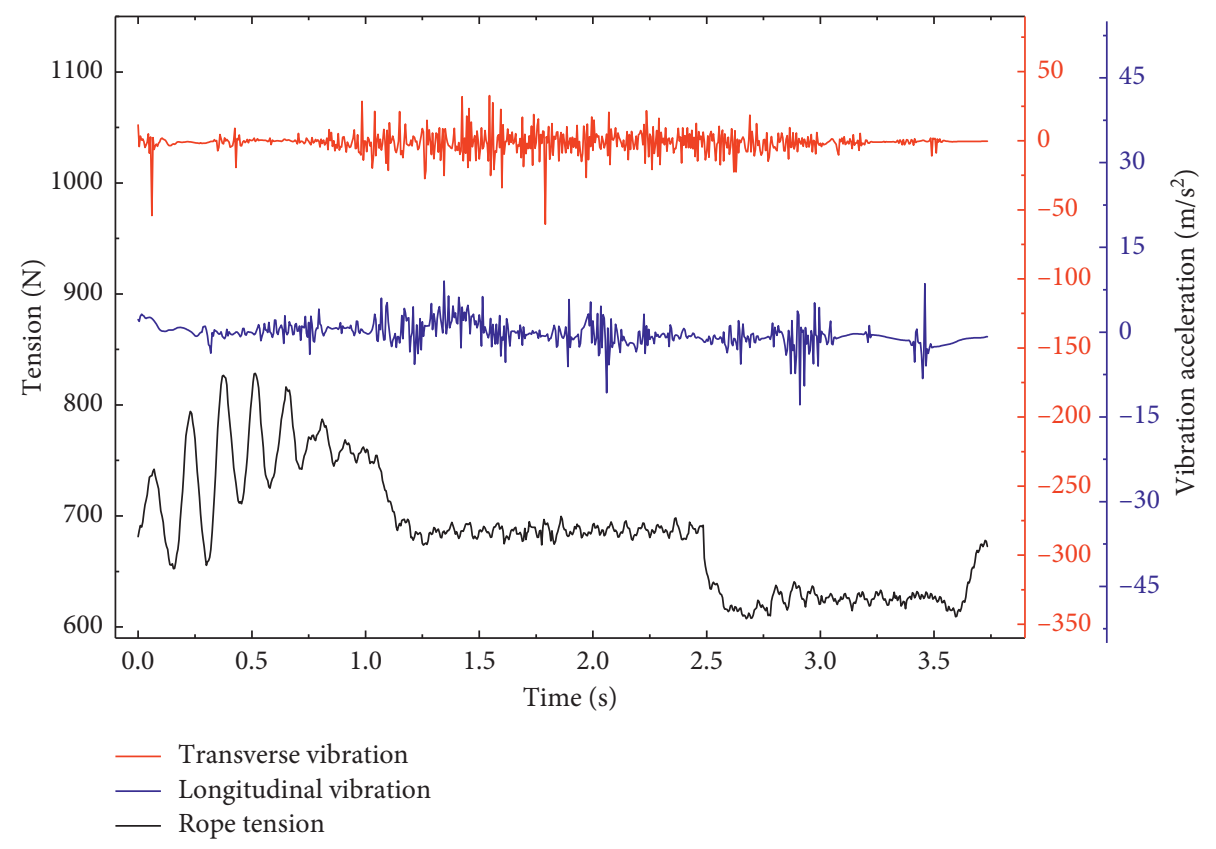

FIgURE 8: Rope tension and vibration without periodic excitation.

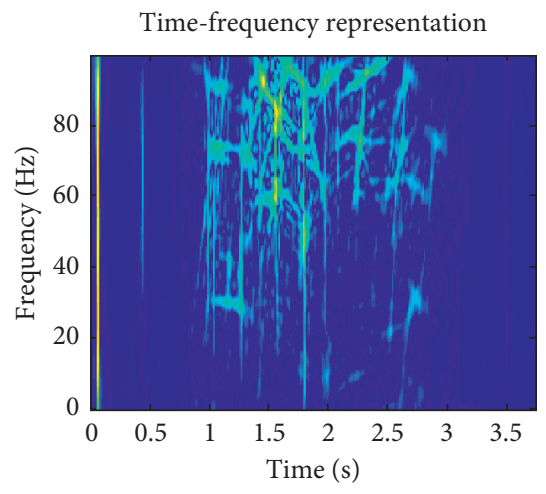

(a)

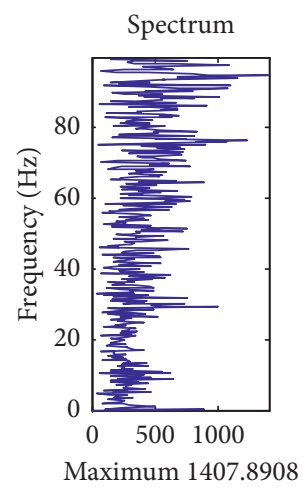

Maximum 1407.8908

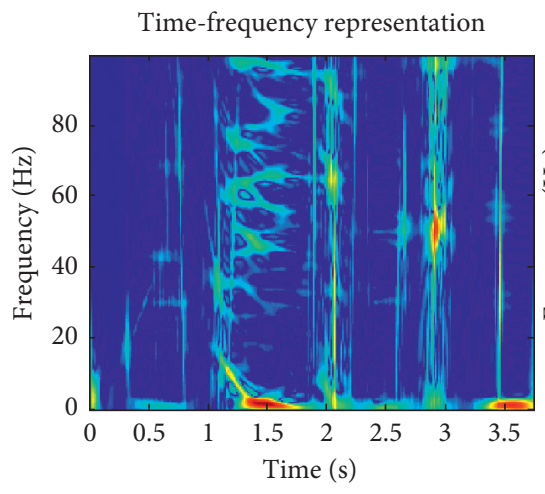

(b)

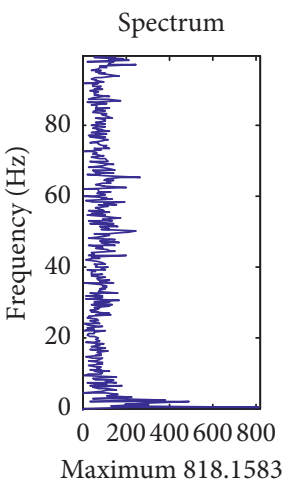

(b) Longitudinal. static excitation before lifting. Compared with the lifting process during nonexcitation, the transverse vibration is not significantly enhanced with the increase in lifting speed. During the lifting process, the longitudinal vibration is more enhanced than the static excitation state before lifting.

The time-frequency distribution in Figure 11 shows that the transverse vibration has a significant horizontal slender component, and the power spectral value is $20946 \mathrm{~m}^{2} \cdot \mathrm{s}$, which is 15 times of the corresponding value $\left(1407 \mathrm{~m}^{2} \cdot \mathrm{s}\right)$ when unexcited. The frequency is constant at approximately $46.7 \mathrm{~Hz}$, so this component is dominated by the excitation frequency. In addition, similar to the time-frequency characteristics of the transverse vibration when unexcited, many corrugated frequency components appear in the range of $60 \sim 100 \mathrm{~Hz}$ in the constant-speed stage [34]. This phenomenon is also related to the increase in lifting speed. Therefore, the transverse vibration of the wire rope under periodic excitation is a typical forced vibration because of the small transverse stiffness and poor displacement resistance of the steel wire rope. The longitudinal time-frequency distribution of the rope under excitation is characterized by many interlaced frequency components, which almost 


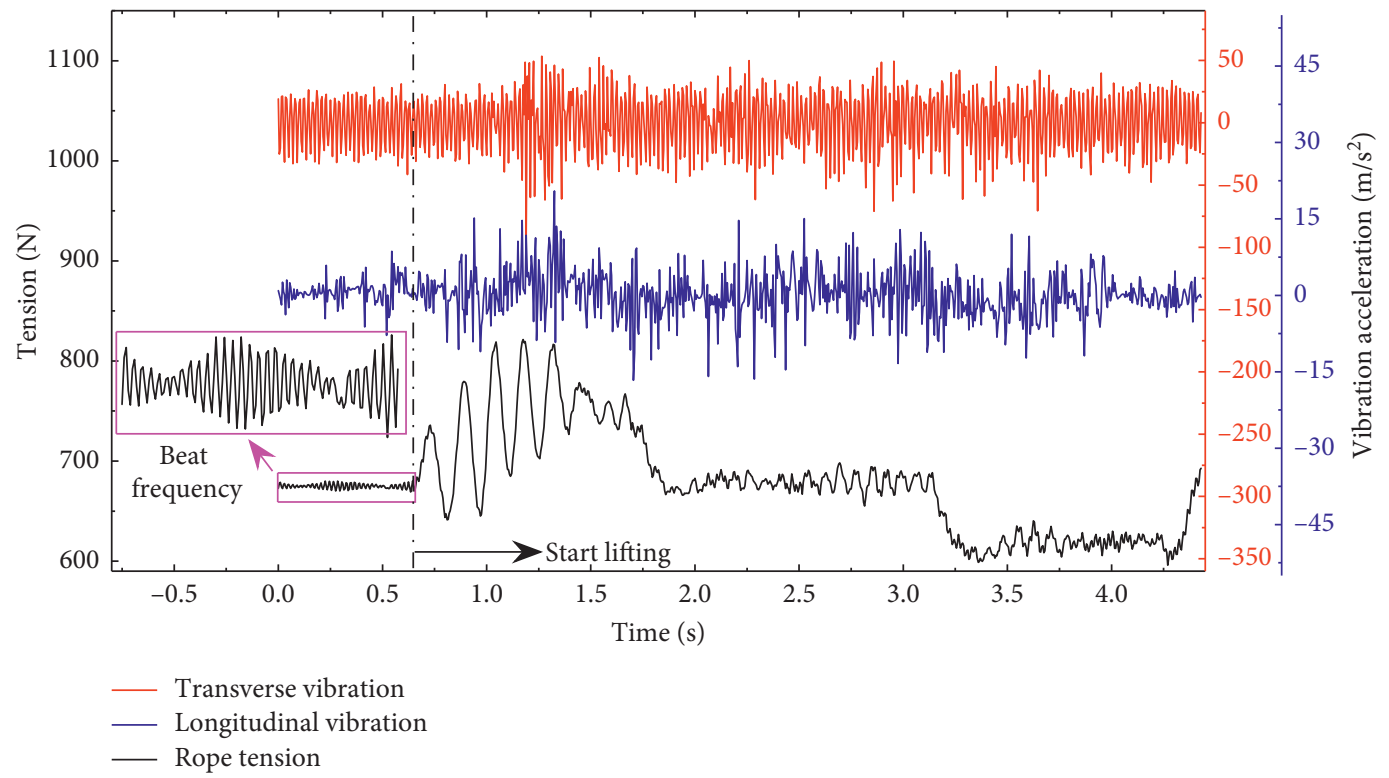

FIGURE 10: Rope tension and vibration under $46.7 \mathrm{~Hz}$ longitudinal excitation.

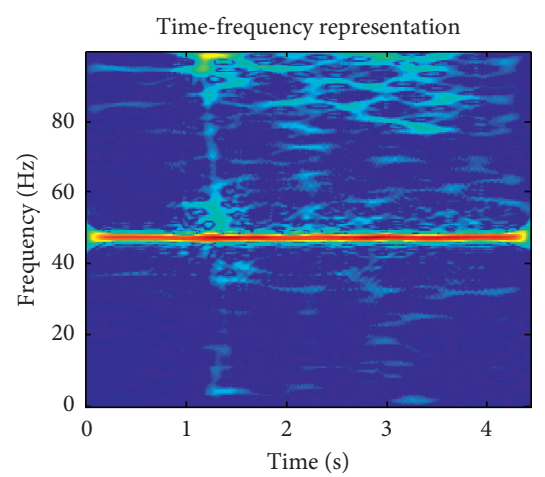

(a)

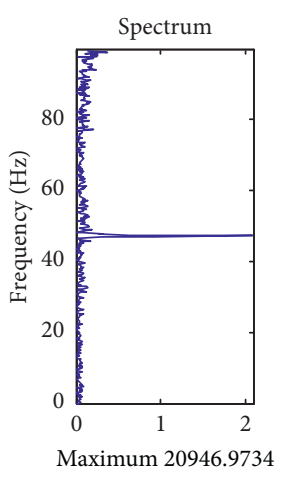

Maximum 20946.9734

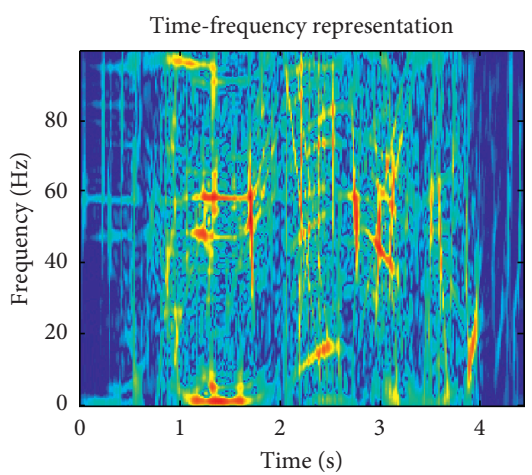

(b)

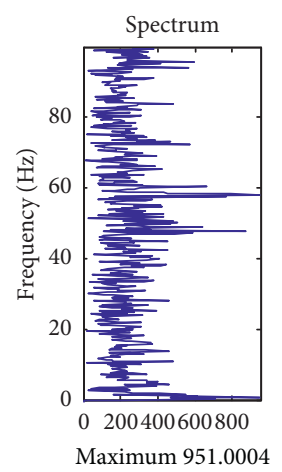

Maximum 951.0004

Figure 11: Time-frequency distribution of the rope vibration under $46.7^{\circ} \mathrm{Hz}$ longitudinal excitation. (a) Transverse. (b) Longitudinal.

occupy the entire time-frequency distribution area. Thus, the effect of the excitation on the longitudinal vibration of the wire rope is randomized, complicated, and unstable. Because the wire rope is long, the excitation wave continuously reflects and overlaps in the wire rope to form a complex dynamic response [35-37]. Since the power spectrum is relatively small and does not form a regular fixed-frequency component, the wire rope absorbs most of the vibration energy because of longitudinal damping and elastic deformation, which embodies the excitation stability of the flexible rope.

3.2. Different Excitation Frequencies. Figure 12 shows the transverse rope vibration acceleration at different excitation frequencies. The lifting process starts at $0.5 \mathrm{~s}$, before which the wire rope is stationary. The transverse vibration of the wire rope at each excitation frequency has a large amplitude enhancement, and the effect of different frequencies on the static state rope is different. Because of the relatively small excitation force, the transverse vibration at $23.6 \mathrm{~Hz}$ is significantly smaller than other frequencies. After the start of the lifting, the transverse vibration amplitude increases in varying degrees at the excitation frequencies above $43.3 \mathrm{~Hz}$. However, compared with the nonexcitation state, it no longer has the symmetrical distribution characteristic that the amplitude increases with the increase in velocity. Instead, the amplitude of vibration increases at a certain moment, and the moment is delayed with the increase in excitation frequency (as shown by the purple arrow). Some evidence can be found in Figure 13 to explain this phenomenon. It can be seen that, in addition to the excitation component of the foundation, the time when the vibration starts to strengthen is really related to the time-frequency distribution, as shown in the black dotted circle in the figure. The strengthening time of vibration amplitude corresponds to the cross-linking points of time-frequency components. This is obviously related to the multistep natural frequency 


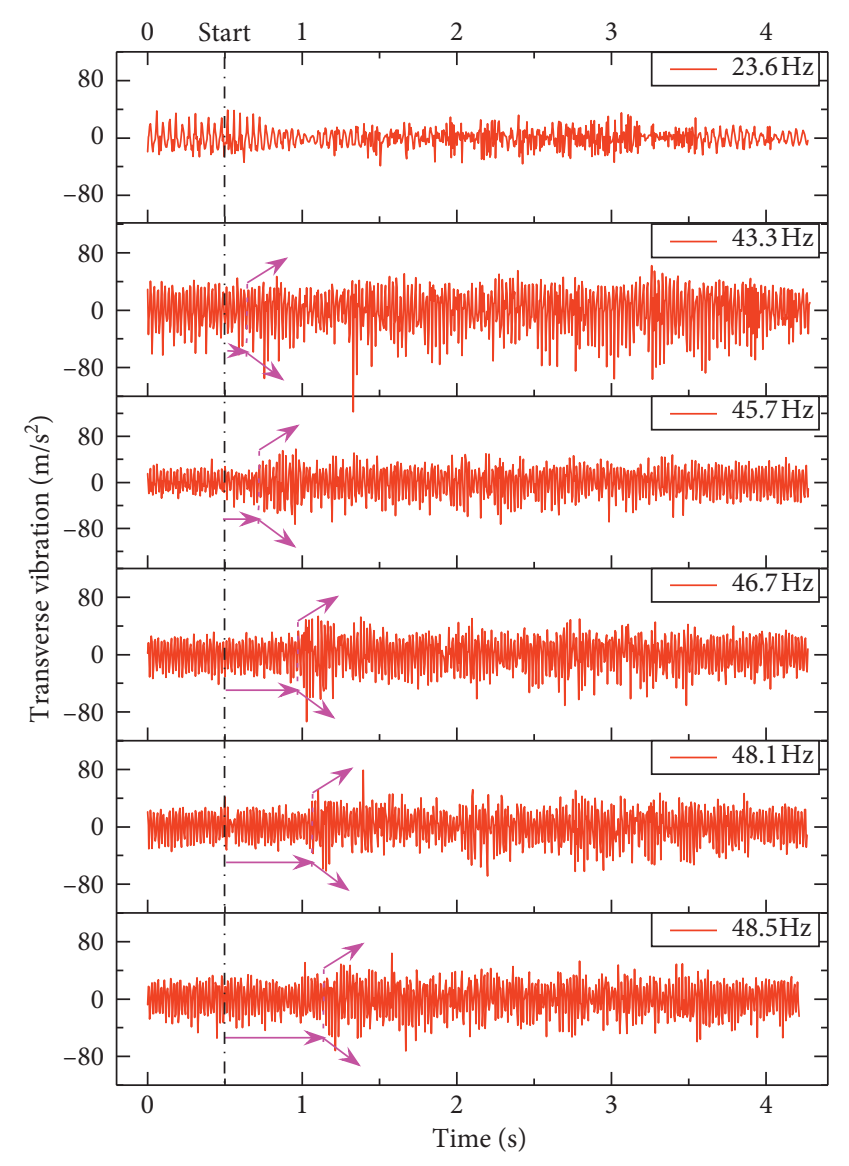

FIgURE 12: Transverse rope vibration under different excitation frequencies.

of the wire rope, that is, different excitation frequencies produce resonance cross-linking with some natural components of the wire rope to increase the amplitude. The results show that the distribution range of natural vibration frequency of the steel wire rope is wide. The maximum amplitude of the transverse vibration in each excitation frequency is -141.5 and $78.7 \mathrm{~m} / \mathrm{s}^{2}$, respectively.

Figure 14 shows the longitudinal vibration acceleration of the wire rope at different excitation frequencies. The longitudinal vibration characteristics under different excitation frequencies are similar to that of the nonexcitation state, which is characterized by random vibration and sudden change. Compared with the transverse vibration, the overall amplitude of the longitudinal vibration is smaller. Compared with the nonexcitation state, the longitudinal vibration of the wire rope is not enhanced as much as the transverse vibration. Similarly, because of the small excitation force at $23.6 \mathrm{~Hz}$ excitation frequency, the enhancement of the vibration amplitude is weak. The amplitude of vibration is strengthened under other excitation frequencies. However, the longitudinal vibration distribution law does not significantly change with the increase in excitation frequencies. Similar to the nonexcitation state, it tends to strengthen with the increase in lifting speed. The maximum amplitude of the longitudinal vibration in the forward and reverse directions at each excitation frequency is -55.1 and $50.5 \mathrm{~m} / \mathrm{s}^{2}$, respectively.
Figure 15 shows the standard deviations of the transverse and longitudinal vibrations at different excitation frequencies. The amplitude of transverse and longitudinal vibrations is still the smallest when the excitation frequency is $23.6 \mathrm{~Hz}$ because of the small excitation force. The standard deviation of transverse vibration reaches a maximum of approximately $30 \mathrm{~m} / \mathrm{s}^{2}$ at $43.3 \mathrm{~Hz}$ excitation frequency. When the excitation frequency continues to increase, this value decreases until it reaches its lowest value at $48.1 \mathrm{~Hz}$ and subsequently increases. The standard deviation of the longitudinal vibration shows a " $V$ " distribution with the increase in excitation frequency, reaches a minimum of $4.56 \mathrm{~m} / \mathrm{s}^{2}$ near $46.7 \mathrm{~Hz}$, and subsequently increases. The standard deviation of the transverse and longitudinal vibrations reflects the average fluctuation amplitude of vibration acceleration. Both of them reach the minimum near $47 \mathrm{~Hz}$ and the maximum near $43.3 \mathrm{~Hz}$ with smaller excitation force, which shows the typical multimodal nonlinear vibration characteristics of the wire rope during dynamic operation $[22,24]$. The superharmonic resonance [38-40] of the wire rope is stimulated when the wire rope is excited near $43.3 \mathrm{~Hz}$. However, the resonance tendency of the wire rope is weak near the excitation frequency of $46.7 \sim 48.1 \mathrm{~Hz}$. This phenomenon is evident from the time-frequency distribution of the transverse vibration (Figure 13).

Figure 13 shows the time-frequency distribution of the transverse vibration of the wire rope at different excitation frequencies. The most prominent characteristics of the transverse vibration under different excitation frequencies are that a horizontal frequency band, i.e., fundamental frequency, which runs through the entire time domain in accordance with the excitation frequency, appears on the time-frequency distribution. In addition to the fundamental frequency, several high-order harmonics are horizontally distributed in the time-frequency diagram, similar to the literature [41]. At excitation frequencies of 23.6 45.7 Hz, several high-order harmonics with different frequencies appear on the upper side of the fundamental frequency in the static state of the first 0.5 seconds. Table 3 lists the harmonic frequencies that occur at the first three excitation frequencies of the stationary state rope. Each harmonic frequency has a certain integer multiple relationship with the fundamental frequency ( 2 and 4 times) or an individual fractional multiple relationship $(72 \mathrm{~Hz})$. Thus, the wire rope can excite types of superharmonics at some excitation frequencies because of the multidegree of freedom flexible property, which is detrimental to the operational stability.

At $23.6 \mathrm{~Hz}$, the fundamental wave of transverse vibration is "truncated" by the lifting motion in the middle of the timefrequency distribution, which presents an intricate state of multifrequency components at 50 and $100 \mathrm{~Hz}$. This phenomenon is similar to the time-frequency characteristics of the transverse vibration in the state of nonexcitation in Figure 9(a). The reason is the higher lifting speed and smaller excitation force at $23.6 \mathrm{~Hz}$, which makes the transverse vibration of the rope more affected by the speed than by the excitation. When the excitation frequency increases to $43.3 \mathrm{~Hz}$, the $72 \mathrm{~Hz}$ and $85 \mathrm{~Hz}$ harmonics generated by the 


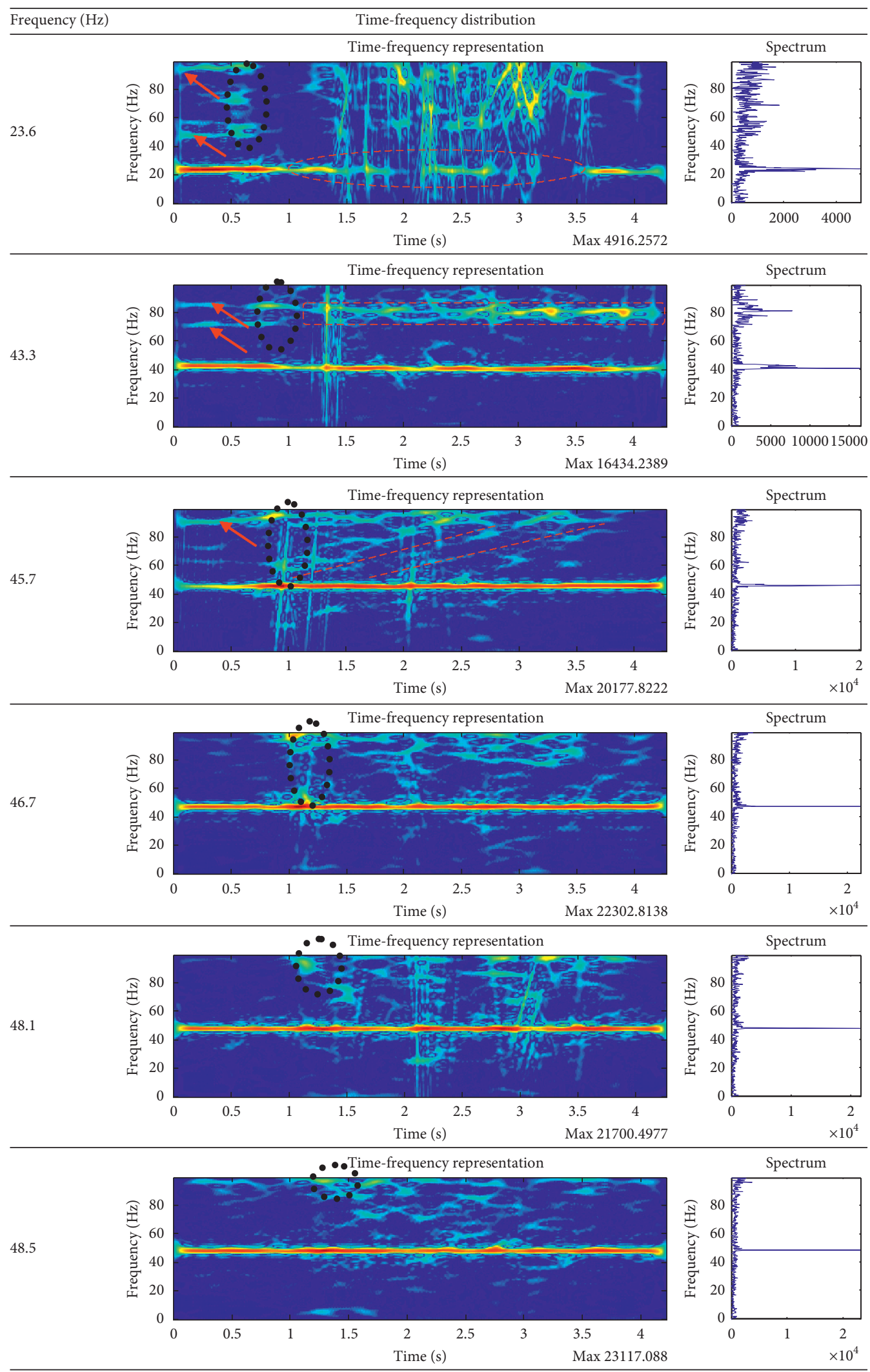

FiguRE 13: Time-frequency distribution of the transverse rope vibration under different excitation frequencies. 


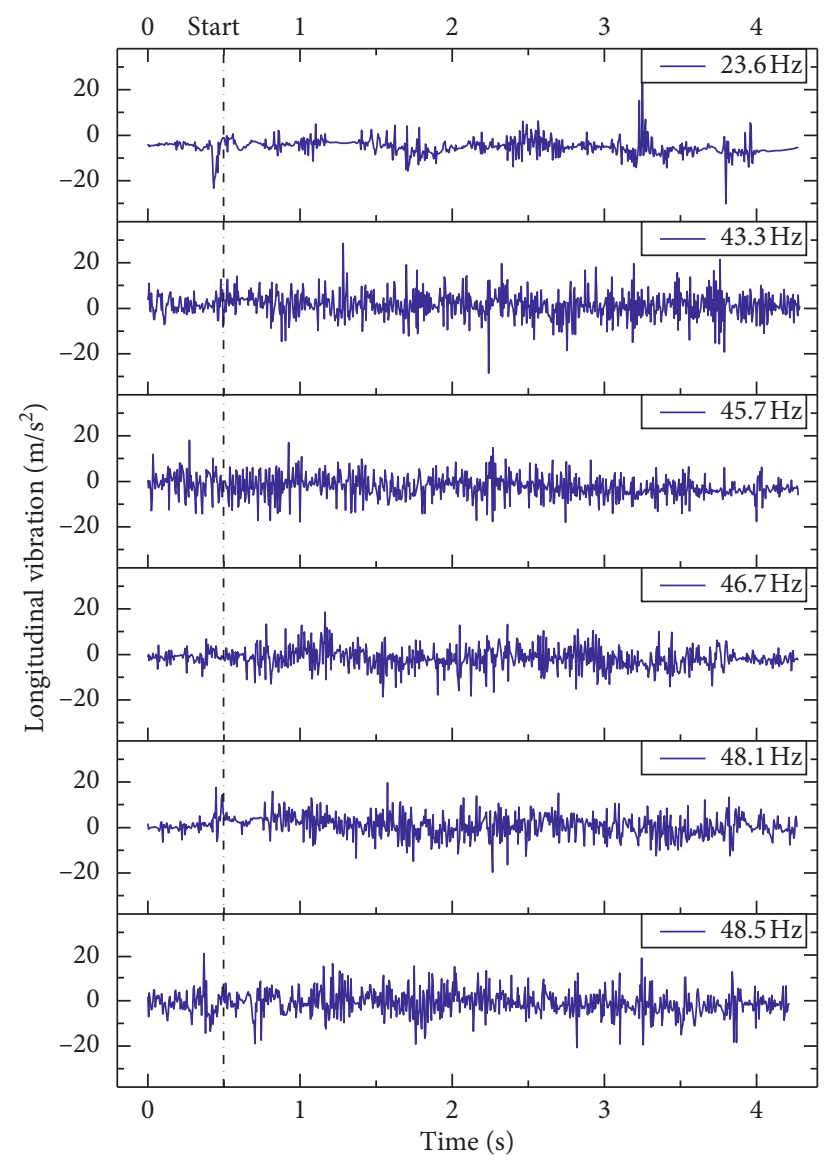

Figure 14: Longitudinal rope vibration under different excitation frequencies.

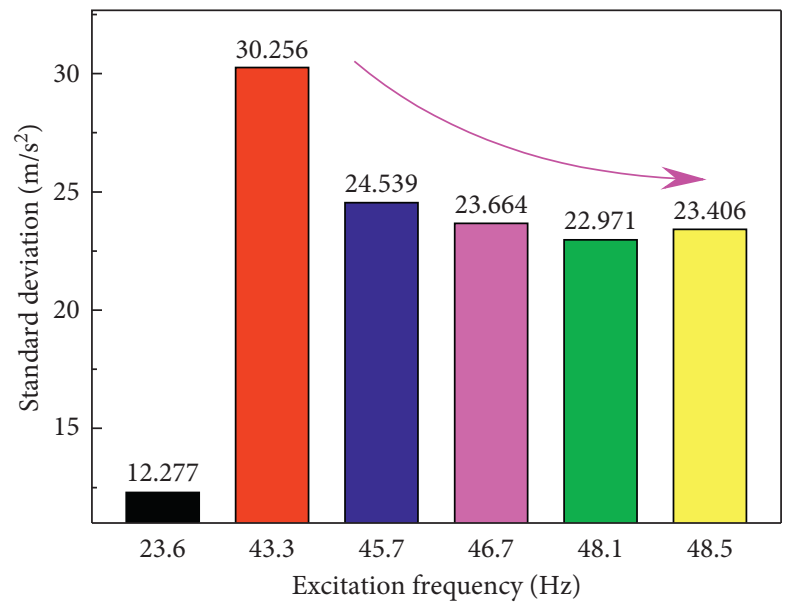

(a)

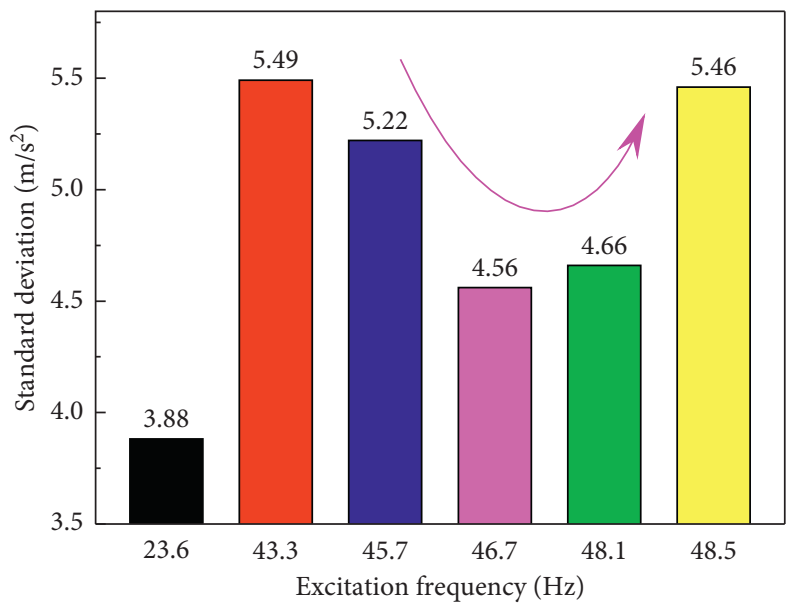

(b)

Figure 15: Standard deviation of the wire rope vibration at different excitation frequencies. (a) Transverse. (b) Longitudinal.

TABLE 3: Main response frequency of the transverse rope vibration under different excitation frequencies.

\begin{tabular}{lcc}
\hline Excitation frequency & Response frequency 1 & Response frequency 2 \\
\hline 23.6 & 48 (twice) & 95 (fourfold) \\
43.3 & 72 & 85 (twice) \\
45.7 & 91 (twice) & $*$ \\
\hline
\end{tabular}



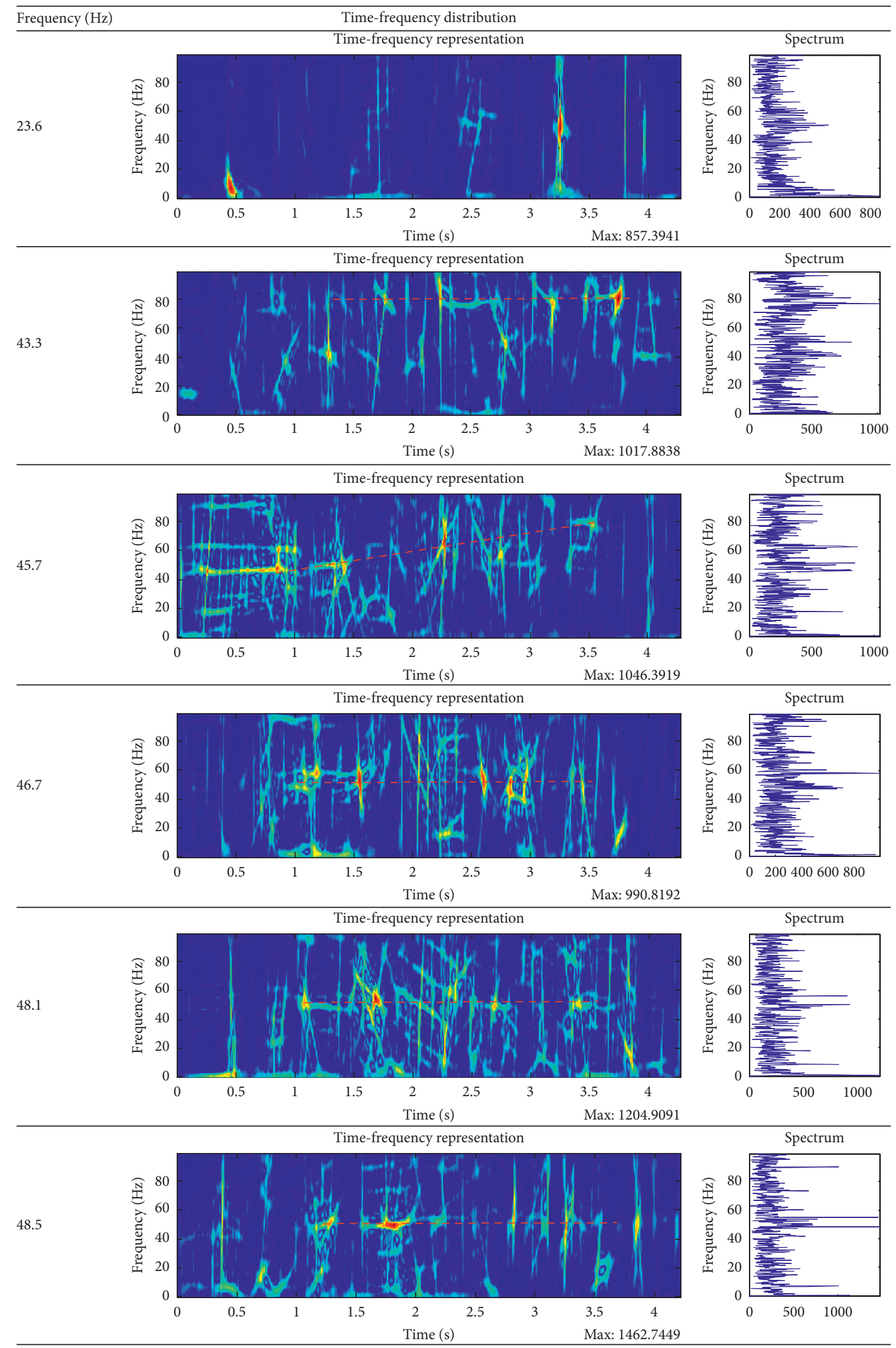

FIGURE 16: Time-frequency distribution of the longitudinal rope vibration under different excitation frequencies.

original static excitation are interlinked after the lifting motion begins. A significant harmonic wave is formed near $80 \mathrm{~Hz}$ in the time-frequency distribution diagram, which explains the phenomenon that the standard deviation of the rope transverse vibration in Figure 15 reaches the maximum when it is excited at $43.3 \mathrm{~Hz}$ [24]. 


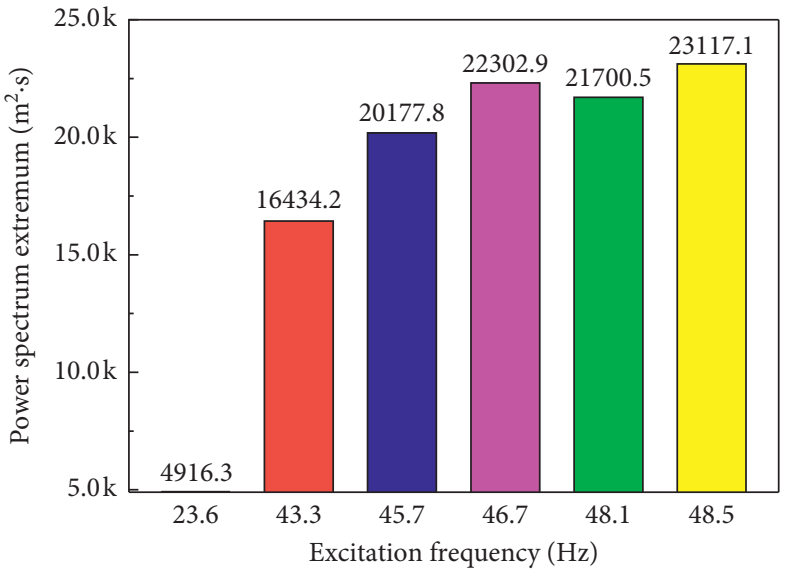

(a)

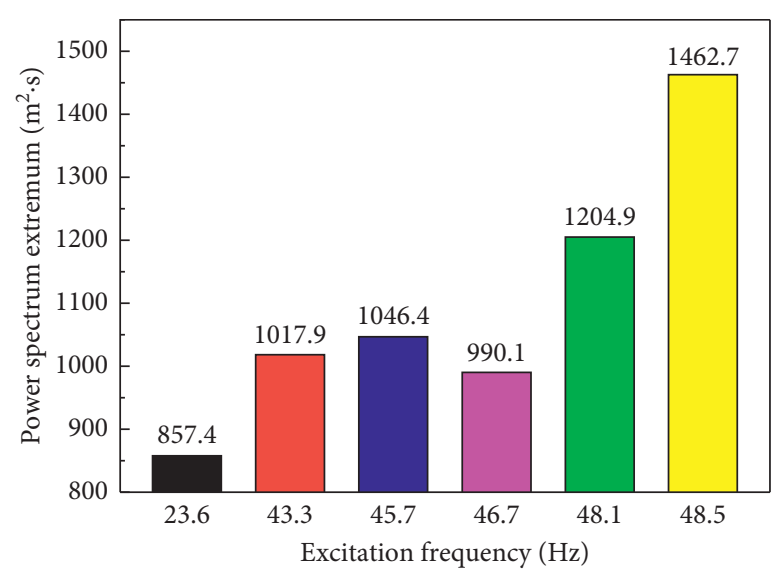

(b)

Figure 17: Maximum rope vibration power spectrum under different excitation frequencies. (a) Transverse. (b) Longitudinal.

When the excitation frequency continues to increase, the distribution of the fundamental frequency remains unchanged, the distribution of other harmonics tends to be flat, and the crosslinkability also decreases. Under the excitation frequency of $46.7 \mathrm{~Hz}$ and above, no horizontal harmonics appear in the time-frequency diagram of the transverse vibration of the static rope. The smaller excitation force at $43.3 \mathrm{~Hz}$ excites a stronger higher-harmonic resonance, whereas the larger excitation force at $46.7 \mathrm{~Hz}$ only excites the forced vibration with the smaller intensity. Thus, $43.3 \mathrm{~Hz}$ is close to the natural frequency of a certain order of the wire rope. It is easy to cause strong harmonic resonance when the excitation frequency is near the natural frequency [38]. Serious cases will pose a threat to the operation of the equipment.

Figure 16 shows the time-frequency distribution of the longitudinal vibration signal of the wire rope. The biggest difference between longitudinal vibration and transverse vibration is that the time-frequency diagram of the longitudinal vibration shows a complex interlaced state of harmonics at various excitation frequencies, and there is no uniform fundamental wave at all excitation frequencies. Therefore, the longitudinal vibration under different excitation states is random vibration. Similar to the transverse vibration, only a few harmonics appear in the time-frequency diagram of longitudinal vibration at $23.6 \mathrm{~Hz}$ excitation frequency, and most of them are in the vertical direction with low crosslinking. Thus, the vibration is caused only at the end of the wire rope when the excitation force is low, not the entire rope. When the excitation frequency increases to over $43.3 \mathrm{~Hz}$, the harmonics of all directions in the time-frequency diagram are interlaced and mixed. The wire rope produces multiple overlaps of incident and reflected waves in the entire range, which shows that the longitudinal behaviour of the wire rope is complex dynamic multifrequency vibration.

The ridges of the relative significant harmonic components in the time-frequency diagram of longitudinal vibration (i.e., the protruding peaks shown in deep red) are connected by the red straight dotted lines. Each ridge is divided on a straight line, and the position of the ridge connection at each excitation frequency is notably close to the position of the fundamental or higher harmonics of the corresponding transverse vibration (Table 3). For example, at $43.3 \mathrm{~Hz}$ excitation frequency, the ridges of the longitudinal vibration time-frequency diagram are located on the horizontal line near $80 \mathrm{~Hz}$. The horizontal distributed harmonics at approximately $80 \mathrm{~Hz}$ also exist in the time-frequency diagram of transverse vibration. Furthermore, at $45.7 \mathrm{~Hz}$ excitation frequency, the longitudinal vibration ridges are located on an oblique line with the frequency that increases from 1 second to 3.5 seconds. There are also inclined distributed harmonics rising during $1 \sim 3.5 \mathrm{~s}$ in the time domain in the transverse vibration. Under the excitation frequencies of $46.7,48.1$ and $48.5 \mathrm{~Hz}$, the ridges of the longitudinal vibration timefrequency and the fundamental waves of the transverse vibration time-frequency are in the same horizontal position in the frequency domain. Therefore, it can be explained that the transverse and longitudinal vibrations of the wire rope under the excitation state belong to two different forms of vibration. Different structures, sizes, and load factors of the wire rope in the transverse and longitudinal directions create the transverse force vibration and longitudinal random vibration. However, because of the interaction of the flexible whole and the longitudinal and transverse directions of the wire rope itself, the vibration of the wire rope has strong transverse-longitudinal coupling characteristics. In this paper, for the first time, the experimental evidence of the coupling characteristics of the transverse and longitudinal vibrations of the wire rope has been found, which is different from the theoretical study of coupled dynamics of the wire rope $[5,42,43]$ or the experimental verification of a single direction $[30,44]$.

Figure 17 shows the histogram of the maximum power spectrum of transverse and longitudinal vibrations of the wire rope at different excitation frequencies. The maximum power spectrum of transverse and longitudinal vibrations increases with the increase in excitation frequency. The maximum power spectrum of transverse vibration is larger than that of the longitudinal vibration. Their ratio can reach 10 20 times above $43.3 \mathrm{~Hz}$, and it increases with the increase in excitation frequency, which indicates the dominant position of the transverse vibration of the wire rope. In addition, the maximum power spectrum of transverse and 
longitudinal vibrations decreases at excitation frequencies of 46.7 48.1 Hz. This result is similar to the standard deviation of the wire rope vibration in Figure 13, and the reason is the same, i.e., the resonance tendency of the wire rope is weak near the excitation frequency of $46.7 \sim 48.1 \mathrm{~Hz}$.

\section{Conclusions}

(1) The periodic excitation conditions of the lifting system container are experimentally simulated. The effect of excitation on the rope tension is not obvious, but the transverse and longitudinal rope vibrations are greatly enhanced. The transverse vibration is a forced vibration following excitation. Longitudinal vibration is characterized by many interlaced harmonic components without obvious fundamental waves. The effect of the excitation is more random, complex, and unstable.

(2) At some excitation frequencies, a series of high-order harmonics in multiple relations to the fundamental wave can be excited by the flexible nature of multidegree-of-freedom of the wire rope. With the linearity of the increase in excitation frequency, the amplitude and intensity of the transverse and longitudinal vibrations deviate significantly from their linearity trend at some excitation frequencies (Figures 15 and 17), and this deviation indicates the typical nonlinear vibration characteristics of the wire rope. The increase or decrease in the harmonic resonance trend is directly related to the excitation frequency and multiorder natural frequency characteristics of the wire rope.

(3) Compared with the static state excitation of the wire rope, the longitudinal and transverse vibration during lifting is stronger. The transverse fundamental wave remains unchanged, and after the lifting begins, there will be additional corrugated highorder harmonics. The longitudinal vibration harmonic component will also substantially increase. In addition, in low-frequency excitation $(23.6 \mathrm{~Hz})$, the transverse fundamental wave is distorted by lifting motion. Thus, the dynamic time-varying characteristics of the lifting process make the system operation unstable.

(4) Under all excitation conditions, the ridge lines in the time-frequency diagram of longitudinal vibration coincide with the distribution of fundamental or higher harmonics of the corresponding transverse vibration. This experiment is the first to reveal the transverse-longitudinal coupling vibration characteristics of the wire rope due to the interaction of transverse and longitudinal vibrations.

\section{Data Availability}

The proposed content is original and does not involve plagiarism with copyright infringement issues. The data used to support the findings of this study are available from the corresponding author upon request.

\section{Conflicts of Interest}

The authors declare that they have no conflicts of interest.

\section{Acknowledgments}

This project was supported by the National Natural Science Foundation of China (Grant nos. 51905237, 51705223, and 51805232) and the Natural Science Foundation of Jiangsu Province (Grant no. BK20191000).

\section{References}

[1] R. S. Crespo, S. Kaczmarczyk, P. Picton, and H. Su, "Modelling and simulation of a stationary high-rise elevator system to predict the dynamic interactions between its components," International Journal of Mechanical Sciences, vol. 137, pp. 24-45, 2018.

[2] J. Zhang, D. Wang, D. Zhang, S. Ge, and D. A. Wang, "Dynamic torsional characteristics of mine hoisting rope and its internal spiral components," Tribology International, vol. 109, pp. 182-191, 2017.

[3] G. Cao, J. Wang, and Z. Zhu, "Coupled vibrations of ropeguided hoisting system with tension difference between two guiding ropes," Proceedings of the Institution of Mechanical Engineers, Part C: Journal of Mechanical Engineering Science, vol. 232, no. 2, pp. 231-244, 2018.

[4] J. Juraszek, "Strain and force measurement in wire guide," Archives of Mining Sciences, vol. 63, no. 2, pp. 321-334, 2018.

[5] J. Wang, Y. Pi, Y. Hu, and X. Gong, "Modeling and dynamic behavior analysis of a coupled multi-cable double drum winding hoister with flexible guides," Mechanism and Machine Theory, vol. 108, pp. 191-208, 2017.

[6] K. Feng, Y. J. Xue, F. Yang, J. S. Li, and B. Du, "Calculation analysis on dynamic stiffness of guide wire rope for mine hoist," Coal Technology, vol. 37, no. 6, pp. 244-246, 2018.

[7] Q. Jian, Y. J. Xue, J. S. Li, S. Y. Zou, and K. Ding, "Calculation analysis on transverse stiffness of guide wire rope for mine hoist," Coal Engineering, vol. 48, no. 10, pp. 18-21, 2016.

[8] C. Y. Zhang, X. M. Cao, and C. M. Zhu, "Study on parametric resonance frequency band of elevator ropes," Journal of Vibration and Shock, vol. 26, no. 10, pp. 165-168, 2007.

[9] S. H. Sandilo and W. T. van Horssen, "On a cascade of autoresonances in an elevator cable system," Nonlinear Dynamics, vol. 80, no. 3, pp. 1613-1630, 2015.

[10] D.-H. Yang, K.-Y. Kim, M. K. Kwak, and S. Lee, "Dynamic modeling and experiments on the coupled vibrations of building and elevator ropes," Journal of Sound and Vibration, vol. 390, pp. 164-191, 2017.

[11] M. H. El Ouni, N. Ben Kahla, and A. Preumont, "Numerical and experimental dynamic analysis and control of a cable stayed bridge under parametric excitation," Engineering Structures, vol. 45, pp. 244-256, 2012.

[12] F. Cluni, V. Gusella, and F. Ubertini, "A parametric investigation of wind-induced cable fatigue," Engineering Structures, vol. 29, no. 11, pp. 3094-3105, 2007.

[13] G. Bartoli, F. Cluni, V. Gusella, and L. Procino, "Dynamics of cable under wind action: wind tunnel experimental analysis," Journal of Wind Engineering and Industrial Aerodynamics, vol. 94, no. 5, pp. 259-273, 2006. 
[14] S. Kaczmarczyk and W. Ostachowicz, "Transient vibration phenomena in deep mine hoisting cables. Part 2: numerical simulation of the dynamic response," Journal of Sound and Vibration, vol. 262, no. 2, pp. 245-289, 2003.

[15] H. Ren and W. D. Zhu, "An accurate spatial discretization and substructure method with application to moving elevator cable-car systems-part II: application," Journal of Vibration and Acoustics, vol. 135, no. 5, pp. 1127-1139, 2013.

[16] J. H. Bao, P. Zhang, C. M. Zhu, and M. Zhu, "Nonlinear vibration analysis of flexible hoisting rope with time-varying length," The International Journal of Acoustics and Vibration, vol. 20, no. 3, pp. 160-170, 2015.

[17] P. Udaykant Jadav, R. Amali, and O. B. Adetoro, "Analytical friction model for sliding bodies with coupled longitudinal and transverse vibration," Tribology International, vol. 126, pp. 240-248, 2018.

[18] Y. Guo, D. Zhang, K. Chen, C. Feng, and S. Ge, "Longitudinal dynamic characteristics of steel wire rope in a friction hoisting system and its coupling effect with friction transmission," Tribology International, vol. 119, pp. 731-743, 2018.

[19] Y. Guo, D. Zhang, X. Yang, C. Feng, and S. Ge, "Experimental research on effect of wire rope transverse vibration on friction transmission stability in a friction hoisting system," Tribology International, vol. 115, pp. 233-245, 2017.

[20] Y. Liu and L. Bergdahl, "Extreme mooring cable tensions due to wave-frequency excitations," Applied Ocean Research, vol. 20, no. 4, pp. 237-249, 1998.

[21] H. Nam and N. T. Nghia, "Estimation of cable tension using measured natural frequencies," Procedia Engineering, vol. 14, pp. 1510-1517, 2011.

[22] M. Lepidi and V. Gattulli, "Non-linear interactions in the flexible multi-body dynamics of cable-supported bridge crosssections," International Journal of Non-linear Mechanics, vol. 80, pp. 14-28, 2016.

[23] V. Gattulli, L. Martinelli, F. Perotti, and F. Vestroni, "Nonlinear oscillations of cables under harmonic loading using analytical and finite element models," Computer Methods in Applied Mechanics and Engineering, vol. 193, no. 1-2, pp. 69-85, 2004.

[24] J. H. G. Macdonald, "Multi-modal vibration amplitudes of taut inclined cables due to direct and/or parametric excitation," Journal of Sound and Vibration, vol. 363, pp. 473-494, 2016.

[25] J. H. G. Macdonald, M. S. Dietz, S. A. Neild, A. GonzalezBuelga, A. J. Crewe, and D. J. Wagg, "Generalised modal stability of inclined cables subjected to support excitations," Journal of Sound and Vibration, vol. 329, no. 21, pp. 45154533, 2010.

[26] L. Chen and L. Sun, "Steady-state analysis of cable with nonlinear damper via harmonic balance method for maximizing damping," Journal of Structural Engineering, vol. 143, no. 2, Article ID 04016172, 2017.

[27] Z. Yan, Y. Zhu, Y. You, and J. Wang, "The response and instability of cross-rope suspension towers under harmonic excitation," International Journal of Structural Stability and Dynamics, vol. 17, no. 10, Article ID 1750124, 2017.

[28] K. Zou, S. Nagarajaiah, and A. Dick, "Asymmetric solutions of SDOF system with wire rope vibration isolator subjected to harmonic excitation," International Journal of Structural Stability and Dynamics, vol. 15, no. 6, Article ID 1450089, 2015.

[29] H. Kang, C. H. Tang, L. K. Quen, A. Steven, and X. Yu, "Parametric resonance avoidance of offshore crane cable in subsea lowering operation through $\mathrm{A}^{*}$ heuristic planner,"
Indian Journal of Geo-Marine Sciences, vol. 46, no. 12, pp. 2422-2433, 2017.

[30] J. Yao and X. Xiao, "Effect of hoisting load on transverse vibrations of hoisting catenaries in floor type multirope friction mine hoists," Shock and Vibration, vol. 2016, Article ID 8598749, 15 pages, 2016.

[31] J. Yao, X. Xiao, A. Peng, Y. Jiang, and C. Ma, “Assessment of safety for axial fluctuations of head sheaves in mine hoist based on coupled dynamic model," Engineering Failure Analysis, vol. 51, pp. 98-107, 2015.

[32] H. Y. Wang, T. Jie, and G. Y. Meng, "Study on the adaptive wavelet threshold denoising method for coal mine hoisting wire rope signals based on novel thresholding function," Insight-Non-Destructive Testing and Condition Monitoring, vol. 60, no. 2, pp. 99-103, 2018.

[33] C. F. F. C. Cunha, A. T. Carvalho, M. R. Petraglia, H. P. Amorim, and A. C. S. Lima, "Proposal of a novel fitness function for evaluation of wavelet shrinkage parameters on partial discharge denoising," IET Science, Measurement \& Technology, vol. 12, no. 2, pp. 283-289, 2018.

[34] S. Rajan and H. G. Davies, "Random superharmonic resonance," The Journal of the Acoustical Society of America, vol. 78, no. S1, p. S87, 1985.

[35] R. Raišutis, R. Kažys, L. Mažeika, E. Žukauskas, V. Samaitis, and A. Jankauskas, "Ultrasonic guided wave-based testing technique for inspection of multi-wire rope structures," NDT \& E International, vol. 62, no. 2, pp. 40-49, 2014.

[36] S. Bischoff and L. Gaul, "Simulation of guided wave interaction with defects in rope structures," Special Topics in Structural Dynamics, vol. 6, pp. 603-609, 2013.

[37] A. G. Razdolsky, "Propagation of longitudinal deformation wave along a lifting rope of variable length," International Journal of Solids and Structures, vol. 48, no. 24, pp. 3359-3364, 2011.

[38] X.-Y. Mao, H. Ding, C. W. Lim, and L.-Q. Chen, "Superharmonic resonance and multi-frequency responses of a super-critical translating beam," Journal of Sound and Vibration, vol. 385, pp. 267-283, 2016.

[39] Z.-A. Yang and G.-F. Li, "The third superharmonic resonance of the belt driver mechanism," Challenges of Power Engineering and Environment, vol. 1-2, pp. 523-526, 2007.

[40] G. Zheng, J. M. Ko, and Y. Q. Ni, "Super-harmonic and internal resonances of a suspended cable with nearly commensurable natural frequencies," Nonlinear Dynamics, vol. 30, no. 1, pp. 55-70, 2002.

[41] C. Y. Zhang and C. M. Zhu, "Calculation method of dynamic natural frequencies of elevator system and vibration-suppression strategy," Journal of System Simulation, vol. 19, no. 16, pp. 3856-3859, 2007.

[42] W. D. Zhu and N. A. Zheng, "Exact response of a translating string with arbitrarily varying length under general excitation," Journal of Applied Mechanics, vol. 75, no. 3, pp. 519$525,2008$.

[43] S. Kaczmarczyk and W. Ostachowicz, "Transient vibration phenomena in deep mine hoisting cables. Part 1: mathematical model," Journal of Sound and Vibration, vol. 262, no. 2, pp. 219-244, 2003.

[44] J. Wu and Z. Kou, "Theoretical coupling longitudinaltransverse model and experimental verification of transverse vibration of rope for multi-rope friction hoisting system," International Journal of Coal Science \& Technology, vol. 3, no. 1, pp. 77-84, 2016. 